\title{
The Impact Of Group Projects On Learning, Teaching And Assessment In A Year 3 BA Course
}

\author{
Emma Abson \\ The Business School
}

\section{Introduction}

The following case study is an analysis of a Level 6 course, on the BA Events Management programme. It explores the effectiveness of group projects as a learning tool, the teaching strategies employed on this course, and the assessment process currently in place. The course is designed to synthesize all elements of the programme to allow students to reflect upon and develop earlier theoretical learning and to encourage students to put theory into practice within a real world context. There is a substantial advanced practical element to the course with students aiming to deliver an event of their own devising in groups of six students. Assessment consists of an individual formative piece, a group pitch assignment, a written group proposal, and an individual reflective assignment.

\section{Teaching}

Delivery of the teaching on this course is through two elements - a block of structured lectures, and tutorial sessions consisting of regular group monitoring sessions, managed by students and observed by tutors.

\section{Lectures}

Lectures take place weekly for one hour, with the intention of linking the key theoretical pathways and offering students the opportunity to apply the theory to their practical work. The lecture content focuses on areas of practice that students may be considering in their own projects at that point in the event planning process.

\section{Tutorials}

The structure of the tutorials is based on the principle of introducing and underpinning the practical element of the course. In theory, the tutor spends the first part of the tutorial in discussion with the group as a whole, incorporating activities such as case studies diagnosis, problem-solving exercises or quizzes. The second half of the tutorial is dedicated to group project meetings with tutor observation, which give tutors a chance to understand the group dynamics and to see who is or isn't engaging with the project. 
This structure is solid and, if the tutor is able to deliver the teaching along these lines, it provides a fantastic learning environment. However, in practice, there are a number of challenges that result in a shift in the delivery, particularly in the second part of the tutorial.

The structure of group project meetings is designed to give students the opportunity to discuss their projects in some detail with the tutors, and the tutor the opportunity to see real progress (or lack of) to the student's learning. However, in practice much of these group discussions tend towards the tutor as mentor or adviser, with the focus on helping students to work in groups and working with them to resolve group issues.

On this particular course, students often cite common difficulties, such as team members who are not engaged, disagreements and conflict within the group, and decision-making issues, as major obstacles to their projects. As Anderson et al (1998: 34) suggest, it is essential that tutors:

"Help students to understand the reasons why group work can go wrong. The more students know about the things that work and the hazards of interpersonal relationships and group dynamics, the better they can cope with the aspects of human nature that inevitably play their part in any kind of group situation."

There is often an assumption that group work will happen naturally for students, but frequently it does not. The provision of training for students on how to operate within a group environment, and preparing them to work effectively as a team member, would help to ensure that learning can take place without obstruction.

It is important to note that feedback suggests that students relish the opportunity to run their own event, despite the problems often cited with group projects. In support of this feedback, Griffiths (2009) points to several research projects that provide strong evidence from students themselves that they benefit from the experience in both cognitive and affective ways:

"Alongside understanding and knowledge benefits, students suggest that participating, belonging and being involved are important dimensions of the experience. The implication of these findings is that the process of building and managing groups, and assisting with the development of relationships is of paramount importance." (Griffiths, 2009:44)

Students on this course report that they like the group meeting environment and find the opportunity to discuss the project with tutors on a group-to-one basis an invaluable learning tool, during which they have the opportunity to reflect on their practical work and discuss key events-related issues with an expert.

\section{Learning}

This course has experiential learning as one of its underlying rationales - in particular, the practical element can be related to Kolb's learning cycle (Kolb D. (1984) Experiential learning: experience as the source of learning and development. Englewood Cliffs, New Jersey: Prentice Hall), where learning is a continuing process requiring experience, reflection, adjustment and re-evaluation and then the application of any enhanced understanding to the problem in order to shape understanding (Cameron, 2010). For this course, the students are required to take an active role - it is a student-centred course, which stresses the students' direct experience and asks them to reflect upon experiences, discuss and theorise them 
during the group meetings, attempt to make sense of the experience and to better understand how to approach the same experience again in the future. However, whether the experiential learning gives an insight into how students learn during a set task is debatable. As such, it is interesting to review some theories that consider this in more detail.

In the 1970s Marton (cited in Fry et al, 2009) carried out empirical research regarding the interaction between a student and a set learning task. Marton concluded that the way a student approaches a task determined the engagement with the subject and the outcomes. The students therefore approached learning on either a deep or a surface level. The deep approach to learning is typified by an intention to understand and seek meaning, leading students to attempt to relate concepts to ensure understanding...to distinguish between new ideas and existing knowledge, and to critically evaluate and determine key themes and concepts. (Fry et al, 2009:10). So, deep learning represents a desire to understand the ideas for yourself, and is born out of an active interest in the subject matter. It represents a "higher level of cognitive processing throughout learning" (11) and it is this state students and tutors alike should strive towards. Students engaging in a surface approach to learning, however, can be typified as undertaking study done without regard for its purpose (Cameron, 2010).

It can be argued that this course forces, as far as is possible, deep learning. Through the practical elements of this course, the students are required to engage in a full exploration of their understanding of the processes, with reflection, evaluation and action as a central part of the success of their events. The course also fosters conditions whereby students can "observe their own learning styles, change these styles to suit different tasks and engage more deeply with the content of the subject" (Griffiths, 2009:74). These latter attributes are often cited as prerequisites for a deep approach to learning.

Biggs (1999), however, has suggested a third approach to learning - the strategic approach - which is of some relevance to the way in which students learn for this course. The strategic approach is associated with assessment and there is an emphasis on organising learning specifically to obtain a high mark. Whilst I argue that this course encourages deep learning and is constructed to make it difficult for the students to employ surface learning techniques, group projects do provide an opportunity for them to also employ techniques from the strategic approach. There is evidence of some students engaging in little activity until just before an assessment is due, and evidence during assessment that little preparation has taken place, as well as some demonstration of a lack of understanding of the processes as a whole. And, of course, a number of disappearing students and weak group members are being carried.

It is my opinion that group projects, whilst perhaps needing more care to organise, supervise and participate in than other learning tools, are an important aspect of university learning - through the group processes, students develop and demonstrate important skills in working together and largely undertake learning on a deep level. Despite the issues surrounding the forming of groups, group dynamics and the ability to undertake strategic learning, the students offer extremely positive feedback and tend to achieve high marks during the assessment process.

\section{Assessment}

Race (2006) suggests that "assessment processes need to address the qualities of reliability and transparency in order to meet UK educational standards and to embrace the aspirations of teaching and learning strategies". 
He proposes that assessment should be reliable - the assessment should be fair and consistent, and the briefings, criteria and marking schemes need to be clear for learners and tutors alike. It is difficult to offer a truly reliable assessment of practical elements as they are often 'live' and happen in a moment. However, this is combated, to some extent, on this course with the requirement that each piece of work is double marked - two tutors are present for each of the practical elements and each piece of written work is viewed by the same two tutors. There is then a conference to discuss marks and to come to an agreement. In this way, the assessment on this course can be said to be as reliable as is possible, given the nature of the set tasks.

The assessment criteria should be transparent; the learning outcomes and assessment criteria should be matched. There is a good attempt to do this within the handbook, but it is not clear that the students always understand the links between the outcomes and assessment processes, or indeed how we intend to assess their evidence (Race, 2006). The teaching attempts, on occasion, to facilitate this understanding in the classroom, and the practical elements can be seen to be fairly transparent. This is not so successful, however, in the written elements.

Another key element of assessment that is relevant to this course is that of authenticity, particularly in relation to the assessment of group projects. Whilst group projects are an important learning tool - not just for the learning related to the course but also due to the learning the experience itself offers - the authenticity of the assessed work is difficult to establish. How is one to tell who did what within the group, when all the assessor really witnesses is the final product? There is an attempt to establish authenticity through the requirement of each group member to participate in a group pitch, but the stronger team members can easily cover for others.

In order to make the assessment process as fair as possible then, the assessment process should build in criterion that ensures that students' individual contributions will be included in the assessment. There are a number of methods of assessment not currently employed that would enable the students to understand that individual contribution will be measured fairly. Race (2006) suggests these could include the provision of logs of meetings, a breakdown of who agreed to do what, and evidence of the contribution of each member. All of these can be prepared by the group and included in the group project report, and they all lend themselves to assessment.

Another suggestion which would help identify student contributions is intra-peer assessment "Students need to know in advance that there will be penalties for being a passenger. It is usual to have some form of intra-peer assessment, where students themselves decide whether or not the group members contributed equally" (Anderson et al, 1998:37). Race et al (2005) discuss peer-assessment in depth and suggest that it helps involve students more closely in their learning and its evaluation, as well as going some way to ensure the students understand what is required of them.

Importantly, peer assessment will encourage students towards deep learning. "The act of assessing is one of the deepest learning experiences" (Race et al, 2005:132). It develops a deepening understanding of what the subject matter involves and also allows students to learn from each other's successes and weaknesses - they have to notice when work is better than their own, and when they see things done badly that can become a learning experience too, that is a case of what not to do. Additionally, any surface or even strategic approaches will be identified by the other group members, and whilst students may be able to hide their lack of contribution from tutors, they cannot do so from their team members. 
There are a few issues around peer assessment which should be noted - reliability can be a problem, and peer assessment is often an emotional process. However, these can be overcome with input from students and moderation from tutors, and the benefits to learning and to students' engagement with the assessment process suggest that the introduction of this tool should be considered.

\section{Learning, teaching and assessment - constructive alignment?}

The theory of constructivism describes learning as a process of transformation, during which students actively construct their knowledge through new experiences, actions and information (Fry et al, 2009:9). Using the principles of constructivism and the alignment of teaching activities with learning outcomes, Biggs coined the phrase 'constructive alignment'. The basic principle for Biggs is the idea that students construct meaning from what they do to learn. The key to constructive alignment is, therefore, that all the areas of the teaching system - aims, teaching strategies, learning outcomes and assessment tasks - are aligned to each other. Central to this is that all areas of the system are tuned to the learning activities (Biggs, 1999). This course is an example of the encouragement of students to construct meaning through their own actions, and it is interesting, therefore, to spend some time considering whether this course is constructively aligned.

Houghton (2004) suggests there are three processes that need to take place to ensure a course is constructively aligned:

\section{(1) Set learning outcomes}

The rationale behind this course is a forum for students to demonstrate an understanding of the theoretical and practical skills essential for a successful career in events management. The learning outcomes are clearly outlined in the course handbook and offer, in my opinion, enough information for the students to understand what is required of them and what outcomes we expect to see.

(2) Select learning and teaching strategies that are likely to enable the students to attain the outcomes

“...we need to consider approaches that require participation that is more active and encourage more high-level learning. Therefore, if we want students to consider that we expect them to synthesize concepts and link them together, then we should consider assessment activities that encourage that behaviour" (Houghton, 2004). This course can certainly be said to use activities that encourage student engagement but this takes place chiefly in the practical assessment elements of the course. In order to fully align the learning and teaching strategies, we need to further incorporate activities that ensure the students are engaging with the theoretical learning, and encourage or require students to carry out activities that meet all of the learning objectives.

\section{(3) Assess the students' outcomes and grade their learning}

The question here is whether the assessment tasks require students to demonstrate that they have met the learning objectives. There is some evidence that the learning outcomes and teaching strategies are on the right path, and this evidence is demonstrated through the delivery of some of the assignments by the students. In particular, the pitching process, which involves each of the groups (and each group member) actively delivering a pitch on the formation of their group and their event planning so far, appears to indicate that the students understand the stated learning outcomes and are working hard to 
achieve them. The same can be said of the actual delivery of the event. However, there is less evidence of alignment between the outcomes, teaching strategies and assessment when considering the written assignments, which are often neglected within the teaching elements of the course.

\section{Conclusion}

This course has as its core a group project, with all teaching, learning and assessment designed around this practical element. This focus on only one element of the course presents a number of issues for teachers and students alike, and my key recommendation is that this course would benefit from a more holistic approach to the teaching, learning and assessment of the entire course content.

The learning on a course with a substantial practical element presents a number of challenges - not least the issues surrounding the forming of groups and group dynamics. These issues can be tackled with increased attention to students' learning needs in this area, and the provision of training for group work. Another major concern for the practical element is the strategic learning of some students, who act as passengers, allowing other team members to complete the work. These problems can be addressed with a review of the assessment tasks. The assessment tasks need to have further detail within the criterion, and should provide opportunities for the students to demonstrate their own learning (as distinct from that of the group). In particular, I believe that the inclusion of vivas and the introduction of peer assessment will not only improve the validity and establish authenticity of the assessments, but will also ensure that the students are able to understand the link between our teaching and their assessments.

Whilst I have made several recommendations for change, with particular emphasis on applying increased attention to delivering teaching, learning and assessment that focuses on the entire course content, I believe that practical projects are a relevant and worthwhile component of student learning. When discussing individual student projects, Anderson et al (1998) make a number of points relevant to group projects; in particular they suggest that the time spent on practical projects or 'learning by doing' must be useful to the student and relevant to the overall learning outcomes of the course. This project represents the only chance for BA Events Management students to demonstrate the integration of their three years of learning and to apply theory to actual event production. Despite the various criticisms outlined within this case study, I firmly believe that this course represents one of the most important learning tools these particular students will undertake during their studies.

\section{References}

Anderson, D., Brown, S., and Race, P. (1998) 500 Tips for Further and Continuing Education Lecturers. London: Kogan Page Limited.

Biggs, J. (1999) Teaching for Quality Learning at University. Buckingham: SRHE and Open University Press.

Cameron, S. (2010) Learning and Reflective Practice. In: Dass. R. (ed.) Personal and Professional Development (1). Pearson Education Limited.

Fry, H., Ketteridge, S., and Marshall, S. (2009) Teaching and Learning in Higher Education. Oxon: Routledge. Griffiths, S. (2009) Teaching and learning in small groups. In: Fry, H., Ketteridge, S., and Marshall, S. (eds.) Teaching and Learning in Higher Education., Oxon: Routledge. 
Compass: The Journal of Learning and Teaching at the University of Greenwich, Issue 4, 2012 Houghton, W. 2004. Engineering Subject Centre Guide: Learning and Teaching Theory for Engineering Academics. Loughborough: HEA Engineering Subject Centre. Available at: <www.engsc.ac.uk/er/theory/ constructive_alignment.asp> [Accessed 18 January 2010].

Jordan, A., Carlle, O., and Stack, A. (2008) Approaches to Learning. Berkshire: Open University.

Kolb D. (1984) Experiential learning: experience as the source of learning and development. Englewood Cliffs, New Jersey: Prentice Hall.

Race, P. (2006) Learning, Teaching and Assessing Study Text. London: The University of Greenwich.

Race, P., Brown, S., and Smith, B. (2005) 500 Tips on Assessment.

Oxon: Routledge Falmer. 